\title{
Novel Compact Design and Investigation of a Super Wideband Millimeter Wave Antenna for Body-Centric Communications
}

\author{
H. M. Arifur Rahman $\left(\mathbb{D},{ }^{1}\right.$ Mohammad Monirujjaman Khan $\mathbb{D D}^{1}$ Mohammed Baz $\mathbb{D}{ }^{2}$ \\ Mehedi Masud $\mathbb{D}^{3}{ }^{3}$ and Mohammed A. AlZain $\mathbb{D D}^{4}$ \\ ${ }^{1}$ Department of Electrical and Computer Engineering, North South University, Dhaka-1229, Bangladesh \\ ${ }^{2}$ Department of Computer Engineering, College of Computers and Information Technology, Taif University, P. O. Box 11099, \\ Taif 21944, Saudi Arabia \\ ${ }^{3}$ Department of Computer Science, College of Computers and Information Technology, Taif University, P.O. Box 11099, \\ Taif 21944, Saudi Arabia \\ ${ }^{4}$ Department of Information Technology, College of Computers and Information Technology, Taif University, P. O. Box 11099, \\ Taif 21944, Saudi Arabia
}

Correspondence should be addressed to Mohammad Monirujjaman Khan; monirujjaman.khan@northsouth.edu

Received 22 August 2021; Accepted 2 November 2021; Published 18 November 2021

Academic Editor: Muhammad Inam Abbasi

Copyright $(2021$ H. M. Arifur Rahman et al. This is an open access article distributed under the Creative Commons Attribution License, which permits unrestricted use, distribution, and reproduction in any medium, provided the original work is properly cited.

\begin{abstract}
This paper presents a novel design for a multiple band millimeter wave antenna with a wide active region in the extremely high frequency (EHF) range. The antenna's performance was tested at three evenly separated frequencies: $60 \mathrm{GHz}$ within the V-band region, $80 \mathrm{GHz}$ within the E-band region, and $100 \mathrm{GHz}$. Simulation exhibits satisfactory results in terms of gain and efficiency, although the efficiency falling tendency for higher frequency persists. As millimeter wave antennas have miniature-like dimensions and low penetration depth into human body layers, the performance of these antennas is less disturbed by the presence of a human body, making them ideal for body-centric wireless communication (BCWC) applications. Thus, a human body model was created virtually with the necessary property data. Simulations are repeated at the same frequencies as before, with the antenna kept close to the constructed human body model. The results were promising as the gains found increased radiation patterns and return loss curves remained almost identical, except some efficiencies that were considered. Some H-plane radiation patterns are changed by the presence of a human body. Although all three frequencies present satisfactory results, $60 \mathrm{GHz}$ is found to be more balanced, but $100 \mathrm{GHz}$ shows better gain and directivity. Multiple band operability makes this antenna suitable for various applications. Finally, a distance-based analysis was conducted to realize the in-depth characteristics of the antenna by placing the antenna at five different gaps from the human body. The result verifies the antenna's category as suitable for bodycentric communications.
\end{abstract}

\section{Introduction}

The millimeter wave, also known as mmWave or millimeter band, is a popular research sector for telecommunication researchers because of its numerous advantages over other lower frequency bands. The spectrum covers the $30 \mathrm{GHz}$ to $300 \mathrm{GHz}$ frequency range, having wavelengths of $10 \mathrm{~mm}$ to $1 \mathrm{~mm}$, from where the name came. The International Telecommunication Union (ITU) refers to this frequency range as extremely high frequency (EHF) because of its extremely higher frequency spectrum.

Millimeter band electromagnetic waves suffer from atmospheric attenuation, which causes them to gradually degrade as they propagate through the environment or air. This attenuation is mostly the result of absorption by environmental components, such as gases and humidity. Absorption increases as the frequency increases, and maximum frequencies can only remain active within several 
meters of distance. Radio waves exhibit better performance in less humid environments. Apart from this limitation, millimeter waves can be highly effective in short-range distances. This limitation also enables designers to reuse frequency to increase efficiency. To utilize this potential, cell sizes are reduced, occupied by fewer cellular network clients. Access point numbers can be higher in short-range operations.

Millimeter wave signals can be used in an extensive area of operation. Antennas designed for mmWaves have very small form factors, which allows them to be equipped with a variety of mobile and wireless network devices and services. mmWave antennas are also known to consume less power and are more power-efficient during operation. These signals are capable of achieving extremely high data transfer rates compared to the smaller frequency bands, which makes them suitable for point-to-point (P2P) high-speed wireless local area network operations. They are currently being used in military operations, security scanners, fire detection radars, airports, and many other short-distance wireless Internet of things, IoT devices, and scientific research [1].

Within the huge spectrum of mmWave, the $\mathrm{V}$-band of $60 \mathrm{GHz}$, more precisely $57 \mathrm{GHz}$ to $54 \mathrm{GHz}$, is kept unlicensed by the Federal Communications Commission (FCC). Due to the lack of various device implementations, this band remains low in traffic worldwide. Because of the permitted accessibility and its other advantages, researchers worldwide are heavily interested in this frequency band. But it has a few drawbacks compared to other frequency bands in the millimeter wave range. This frequency band coincides with the harmonics of the oxygen molecules in the air and thus gets absorbed so easily into the Earth's terrestrial environment. So the bandwidth delivery distance becomes shorter at this particular frequency $[1,2]$. The range of 70 to $80 \mathrm{GHz}$ of the E-band is also made publicly accessible by the FCC with an easy licensing procedure. In June 2020, the American aerospace manufacturer and space transportation service, SpaceX, applied for the utilization of this band for their orbital deployment and operating authority for the SpaceX Gen2 NGSO satellite system [3]. However, in environments without obstacles like brick walls or metal barriers, and for short-range operations, millimeter waves can achieve an extremely high data transfer rate between portable electronic devices, which can be used for fast file transfer, high definition video streaming, short-range wireless fidelity (WiFi), and much more. Such environments can be found in halls or in medical wards in a hospital.

For body-centric communication, several sensor nodes are placed on, inside, or in close proximity to the human body to collect vital information and send it to a common node where the data is fetched. Mostly, these collected data need to be either stored on a base station computer or sent to a distantly located doctor or physician or to a monitoring healthcare center. Tiny microchip antennas are used as the medium as the sensor nodes are dispersed throughout the body and wires will make it more sophisticated or sometimes impossible to maintain a connection. As a result, it is more commonly known as the body-centric wireless network (BCWN), which is also associated with the wireless body area network (WBAN). These are specially used for medical purposes to distantly monitor someone's vital signs like heartbeat rate, blood pressure, electrocardiogram (ECG), or peripheral oxygen saturation (SpO2) reading collection. In healthcare centers, these can also be used for athletes in sports or astronauts in space [4].

As antennas play a key role in body-centric wireless communication, researchers must keep in mind while designing an antenna how it will perform when it is in close proximity to a human body. Antennas near the human body behave differently than they do in free space. The capacitive properties of the human body are most likely to disturb the performance as well as the efficiency of the antenna [5-7]. The presence of a human body close to an antenna has a notable influence on the radiation efficiency, resonant frequency, radiation patterns, and the input impedance of the model [5-7]. To simulate the performance of an antenna close to a human body, a human body model should be created consisting of three different layers: a thinner skin layer with a loss tangent of 1.37 , a comparatively less thin fat layer with a loss tangent of 0.27 adjacent to it, and a muscle layer with a loss tangent of 0.0012 , respectively [8].

Christophe Calvez et al. previously characterized and analyzed millimeter wave antenna solutions for $60 \mathrm{GHz}$ operation using both SoC (System on Chip) and SiP (System in Package) techniques. Comparing a planner dipole antenna on chip (SoC) with a silicone substrate and Si-IPD in a package antenna, researchers found $\mathrm{SiP}$ antennas can achieve better gains and are mostly suitable for industrial use [9]. A very simple rectangular-shaped patch antenna was designed by Adamu [10]. It is powered by a coaxial probe feed, operates at $38 \mathrm{GHz}$, and is claimed to have $90 \%$ power efficiency. Choi et al. have designed a miniature mmWave $5 \mathrm{G}$ antenna and fabricated it with anodized aluminum oxide (AAO). Researchers claimed they had used 99.99\% pure aluminum thin sheet, which reduces the antenna volume and weight, making it suitable for mobile devices. The antenna operates at $29 \mathrm{GHz}$ and has a gain of $5.02 \mathrm{~dB}$ to $5.62 \mathrm{~dB}$ [11].

Many researchers have tried to design a flawless millimeter wave antenna with high gain and efficiency in the past decade, but very few of them have performed satisfactorily when it comes to the human body. The antenna must perform at least within an excellent operable region for body-centric wireless communication. A mmWave antenna consisting of two identical patch arrays set up faceto-face $19.5 \mathrm{~cm}$ apart fed by a coaxial feed launcher operates within the 37 to $39 \mathrm{GHz}$ frequency range with an optimized gain by Cheng-Nan $\mathrm{Hu}$ et al. [12] but has an unknown performance near the human body, as the model does not appear to be suitable for BCWN. Heba Shawkey and Dalia Elsheakh suggest a dual-meander line (DML) antenna for body-centric networks and biomedical applications that works in several bands: $22 \mathrm{GHz}, 34 \mathrm{GHz}, 44 \mathrm{GHz}$, and $58 \mathrm{GHz}$. The design used a UMC $180 \mathrm{~nm}$ complementary metal oxide semiconductor (CMOS) fabrication process with a low-resistivity silicon substrate and an interdielectric layer embedded with six metal layers. A dielectric passivation layer was applied to the M6 top metallic surface 
TABLe 1: Electrical size at different frequencies.

\begin{tabular}{|c|c|c|c|c|}
\hline Material & $\begin{array}{l}\text { Physical size } \\
(\mathrm{mm})\end{array}$ & $\begin{array}{c}\text { Electrical size at } 60 \mathrm{GHz} \\
(\lambda)\end{array}$ & $\begin{array}{c}\text { Electrical size at } 80 \mathrm{GHz} \\
(\lambda)\end{array}$ & $\begin{array}{l}\text { Electrical size at } 100 \mathrm{GHz} \\
(\lambda)\end{array}$ \\
\hline Length of the substrate & 8 & 0.625 & 0.468 & 0.375 \\
\hline Width of the substrate & 5.2 & 0.96 & 0.72 & 0.576 \\
\hline Height of the substrate & 1.57 & 3.18 & 2.388 & 1.91 \\
\hline $\begin{array}{l}\text { Length of the radiating } \\
\text { element }\end{array}$ & 3.178 & 1.57 & 1.179 & 0.94 \\
\hline $\begin{array}{l}\text { Width of the radiating } \\
\text { element }\end{array}$ & 2.432 & 2.055 & 1.54 & 1.233 \\
\hline $\begin{array}{l}\text { Height of the radiating } \\
\text { element }\end{array}$ & 0.035 & 142.85 & 107.14 & 85.71 \\
\hline
\end{tabular}

[13]. To compare the human body effect, simulations placed the antenna inside and over the human body and observed the downshift of the resonant frequency and operating bandwidth increment. A textile antenna for wearable bodycentric networks has been presented by Chahat et al., which operates in the mmWave frequency range. It was claimed to be the first time that it was implemented with a hybrid textile substrate and that it operates at a frequency range of $57 \mathrm{GHz}$ to $64 \mathrm{GHz}$ [14]. The authors of [15] presented a novel and compact shaped textile substrate for bodycentric communications based on a $60 \mathrm{GHz}$ mmWave antenna. A comparison of antenna performance parameters was conducted utilizing various textile substrates. The proposed antenna of the paper [15] was also tested by placing it on a three-layer human body model. In [16], a Yagi-Udah cotton-based mmWave antenna for on-body communication was presented. The antenna works at $60 \mathrm{GHz}$ and it is bigger in size. According to the authors in [17], a printed antenna for mmWave body-centric communication is presented which operates at $60 \mathrm{GHz}$. The antenna has a length and width of $14 \times 10.5 \mathrm{~mm}$.

The major contribution of this paper is to propose a novel and compact design for a multiband and super wideband mmWave antenna, and its free space and human body performance are simulated and compared. Performance was tested at three different frequencies $(60 \mathrm{GHz}$, $80 \mathrm{GHz}$, and $100 \mathrm{GHz}$ ) within the popular mmWave range. A virtual human body model was created consisting of layers to evaluate its performance over a human body at the same frequencies as the body-centric network. According to the reported literatures in this manuscript, it is noted that most of the mmWave antennas are bigger in size, and they work at lower frequency bands. The maximum operating frequency band was $60 \mathrm{GHz}$ in the presented literatures. However, the proposed antenna is the smallest mmWave antenna to the best of knowledge of the authors of this paper. The overall length and width of this antenna is 8 and $5.2 \mathrm{~mm}$, respectively. The antenna is novel because it works multiple band at the higher frequency bands, and it has super wideband characteristics. In previous studies, researches have not investigated $60 \mathrm{GHz}, 80 \mathrm{GHz}$, and $100 \mathrm{GHz}$ multiband compact and wideband antenna for BCWC. This proposed antenna presents very good performance. Hence, this antenna beats the state of the arts and is considered to be the novel antenna in BCWC application.
The remainder of the paper is divided into the following sections: The antenna's design is described in Section 2. Section 3 includes free space simulation in different bands and performance parameters. In Section 4, human body performance compared to free space was presented. Section 5 contains the evaluation of BCWC compatibility by distance-based study, and, finally, in Section 6, the conclusion was drawn based on the result comparisons.

\section{Antenna Design}

Computer Simulation Technology (CST) Microwave Studio Suite was used to build and test the antenna design. The radiating element, substrate, and ground plane were the three neighboring planner components in the model. The overall length and width of the antenna are $8 \mathrm{~mm}$ and $5.12 \mathrm{~mm}$, respectively. The total thickness of all three layers is $1.57 \mathrm{~mm}$, while the radiating patch is $0.035 \mathrm{~mm}$, the substrate is $1.5 \mathrm{~mm}$, and the ground is $0.035 \mathrm{~mm}$ thick, respectively. The wavelength of the antenna for the operating frequencies of $60 \mathrm{GHz}, 80 \mathrm{GHz}$, and $100 \mathrm{GHz}$ is $5 \mathrm{~mm}$, $3.75 \mathrm{~mm}$, and $3 \mathrm{~mm}$, respectively. Table 1 summarizes the electrical size of the antenna at different frequencies. Figures 1(a)-1(e) show the antenna design, parameters, and front and back views with detailed dimensions. The substrate is made of flame retardant fiberglass reinforced epoxy (FR-4) with a dielectric constant of 3. An inverted lotus petal-shaped cutout ground plane actually consists of four parts: a circular part, a triangular cutout at the bottom of it, a top-left rectangular shape cutout, and an added small rectangular brick on that cutout pace. Annealed copper was selected for the ground. The radiator patch is placed on the upper side of the substrate with a feed line and a waveguide port at the base for source excitation. The feed line is $3.136 \mathrm{~mm}$ long and $0.832 \mathrm{~mm}$ wide. The elliptical half-cylinder has a radius of $1.216 \mathrm{~mm}$ and a vertical axis radius of $1.76 \mathrm{~mm}$. A $0.064 \mathrm{~mm}$ wide equilateral triangular slot $1.92 \mathrm{~mm}$ of each arm is cut in the middle for a better response. The middle rectangle is $1.28 \mathrm{~mm}$ long and $0.576 \mathrm{~mm}$ tall, with $0.128 \mathrm{~mm}$ slots on top and bottom. On the opposite side of the substrate, the circular slot is centered in the middle horizontally but vertically $4.768 \mathrm{~mm}$ higher from the bottom. The radius of the circular shape is $2.128 \mathrm{~mm}$. The rectangular cutout has a dimension of $5.12 \mathrm{~mm} \times 3.52 \mathrm{~mm}$. The length of the bottom triangular extruded sides has been given in Figure 1(e). 

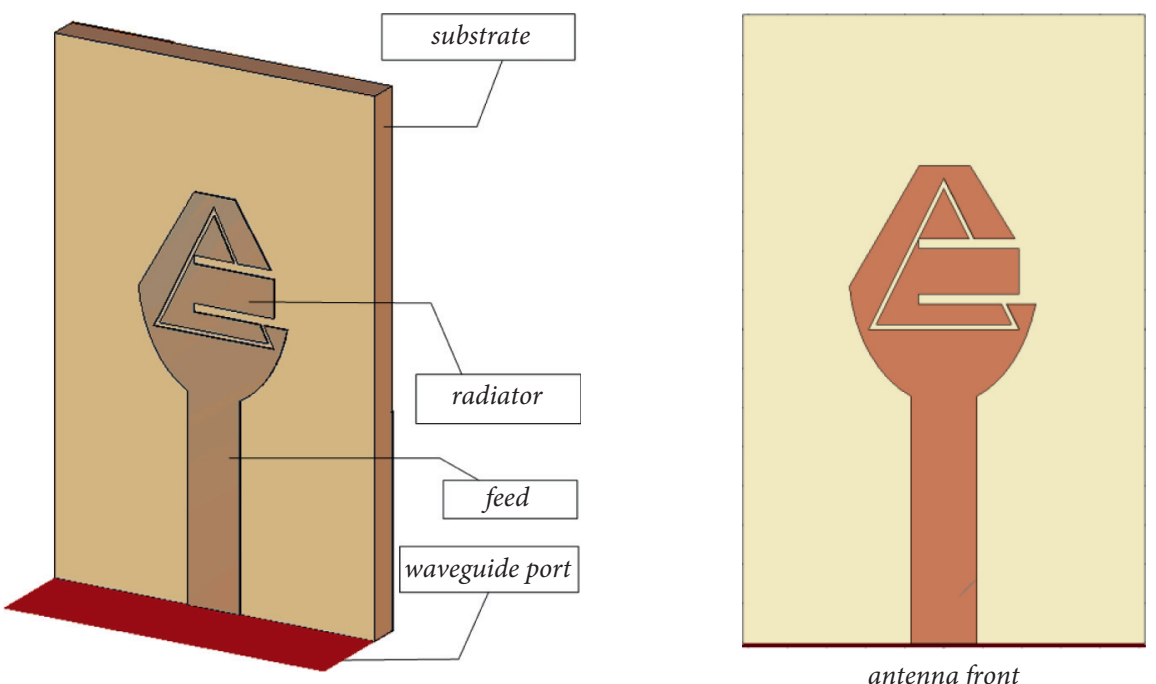

(a)

(b)

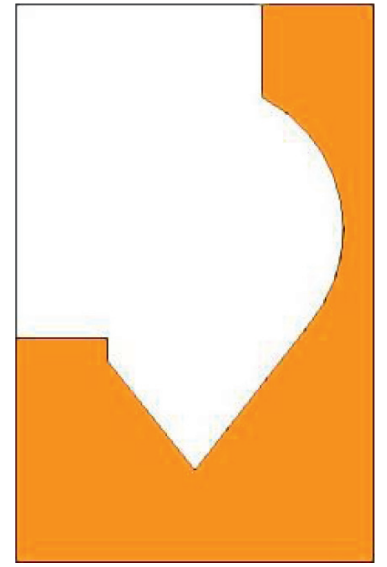

antenna back

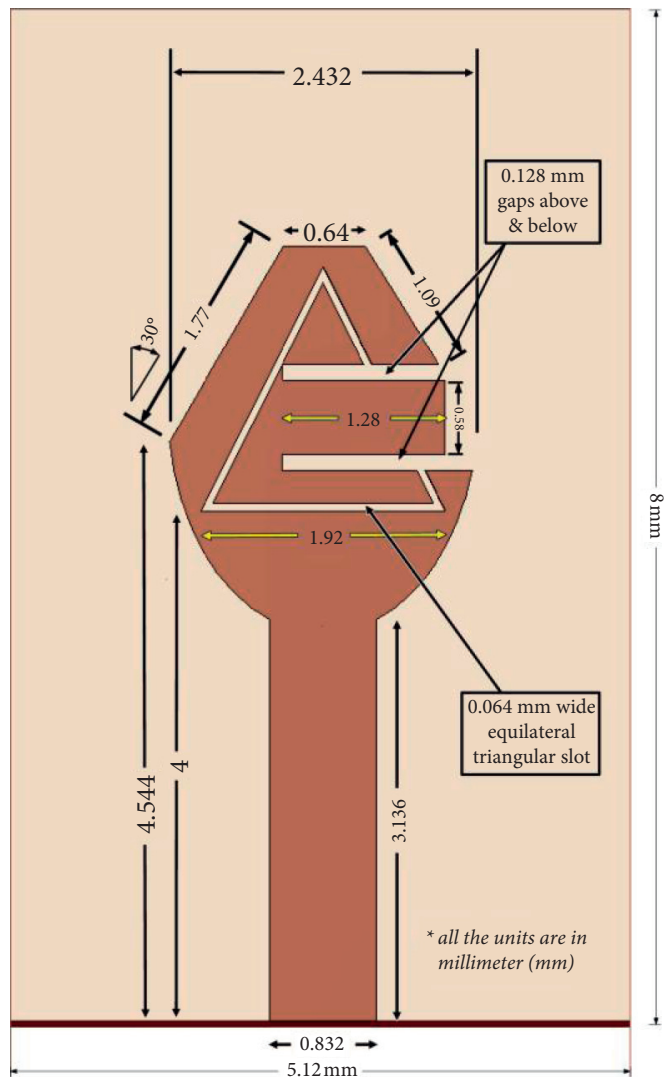

(c)

(d)

FIgURE 1: Continued. 


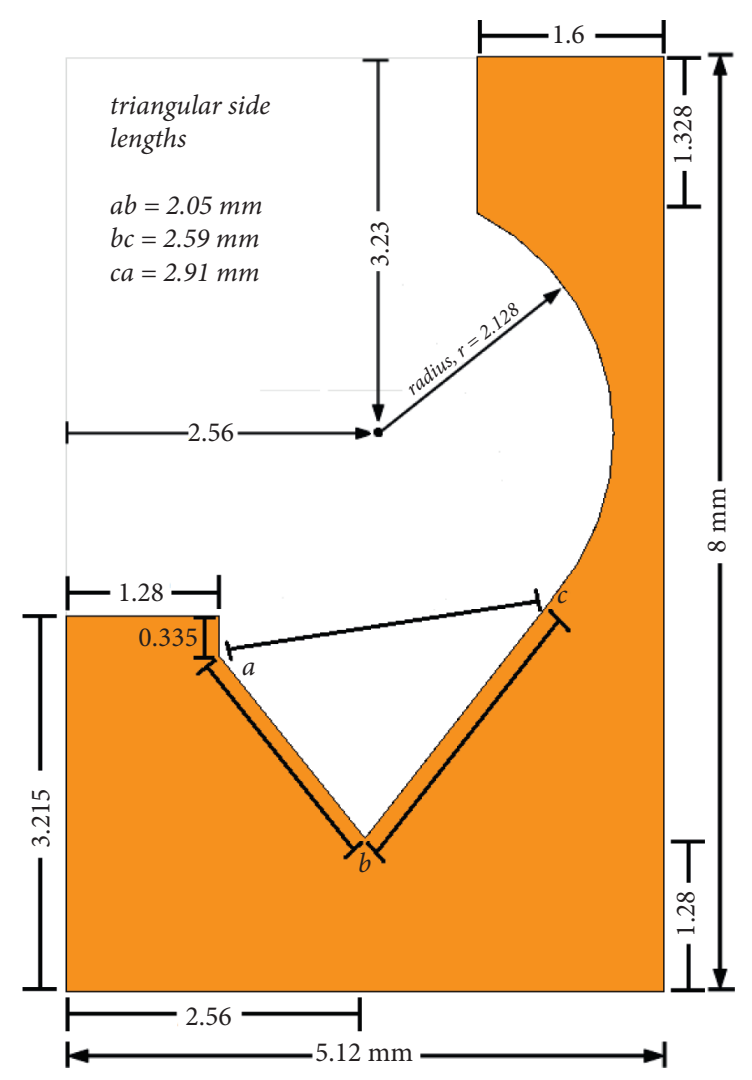

(e)

Figure 1: Antenna design and parameters (a) 3D view, (b) front view, (c) back view, (d) front view with dimensions, and (e) back view with dimensions.

\section{Free Space Simulation}

For the excitation, a waveguide port has been placed on the bottom of the antenna by touching the feed line. Three frequencies are selected from the mmWave range for performance analysis. These frequencies are separated by $20 \mathrm{GHz}: 60 \mathrm{GHz}, 80 \mathrm{GHz}$, and $100 \mathrm{GHz}$. For free space analysis, return loss response, 3D and polar plot radiation patterns from two different planes, gain, radiation efficiency, and total efficiencies were calculated. Simulations were done on a Windows-based modeling and simulation app, CST Microwave Studio Suite.

3.1. Return Loss Response. Figure 2 shows the return loss response curve for the proposed compact antenna in the $50 \mathrm{GHz}$ to $110 \mathrm{GHz}$ range in free space. Almost all the spectrum stays in an active region under $-10 \mathrm{~dB}$. Three selected frequencies were marked, and their corresponding return loss values in $\mathrm{dB}$ are shown in the bottom-right corner. Three resonant frequencies can be clearly seen in the figure too that have been considered for the performance parameters analysis. The return loss values are excellent and below $-10 \mathrm{~dB}$. The return loss values at $60 \mathrm{GHz}, 80 \mathrm{GHz}$, and $100 \mathrm{GHz}$ are $-22.802 \mathrm{~dB},-24.716 \mathrm{~dB}$, and $-16.087 \mathrm{~dB}$, respectively. The bandwidth of this antenna is very wide, as can be seen from Figure 2.

\subsection{Free Space Radiation Patterns}

3.2.1. 3D Patterns. Figures 3(a)-3(c) show the $3 \mathrm{D}$ radiation patterns of the antenna for $60 \mathrm{GHz}, 80 \mathrm{GHz}$, and $100 \mathrm{GHz}$. This antenna's three-dimensional emission patterns are almost omnidirectional, with some deformation at certain directions.

At higher frequencies, the distortion is greater in comparison with the lower frequencies. From Figure 3(a), a $3 \mathrm{D}$ pattern for $60 \mathrm{GHz}$ with a maximum gain of $4.67 \mathrm{~dB}$ is spotted on the XY-plane between the positive $X$-axis and the $Y$-axis. Figure 3(b) for $80 \mathrm{GHz}$ shows maximum gain directed in the same plane but slightly bent to the positive $X$ axis. The recorded gain is $4.12 \mathrm{~dB}$. In Figure $3(\mathrm{c})$, for $100 \mathrm{GHz}$, the maximum gain is $6.54 \mathrm{~dB}$, which is towards the positive $Y$-axis. Another almost symmetrical lobe with a similar gain can be seen on the negative $X$-axis.

3.2.2. Polar Plot Radiation Patterns. For all three frequencies $(60 \mathrm{GHz}, 80 \mathrm{GHz}$, and $100 \mathrm{GHz})$, the polar plot radiation patterns are presented in both the XY- and YZ-planes. Figures $4(\mathrm{a})$ and $4(\mathrm{~b})$ show the polar plot radiation patterns of the antenna for the XY-plane and YZ-plane at $60 \mathrm{GHz}$, $80 \mathrm{GHz}$, and $100 \mathrm{GHz}$.

Figure 4(a) portrays a polar plot radiation pattern for all three frequencies in the XY-plane. For $60 \mathrm{GHz}, 80 \mathrm{GHz}$, and 


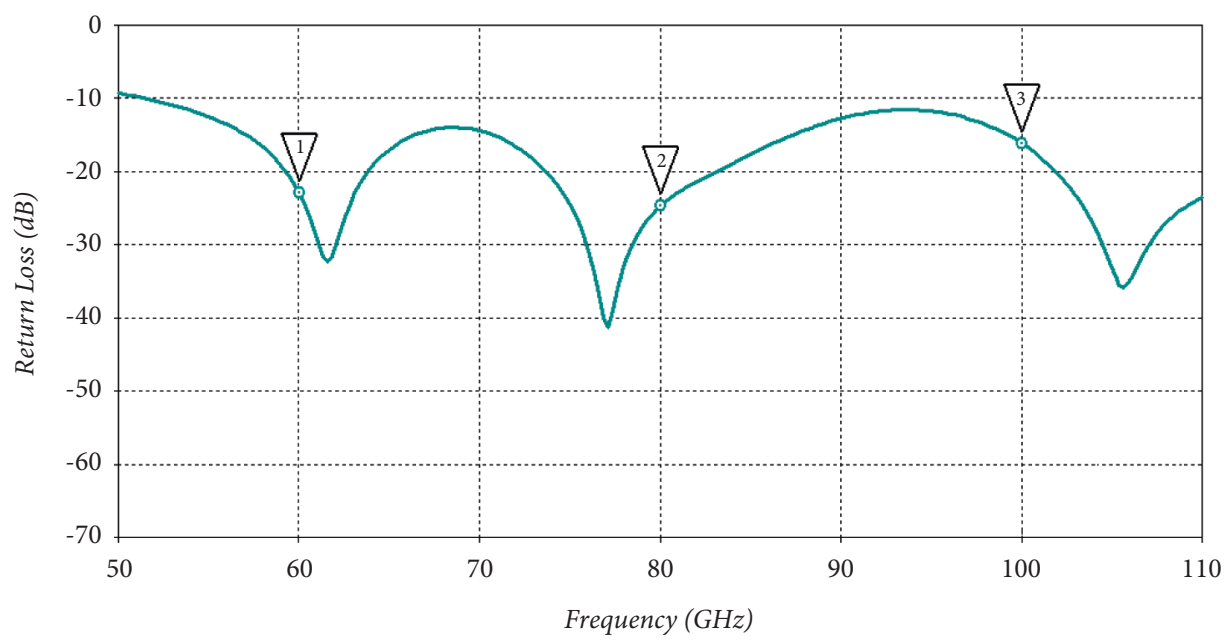

$\odot_{1}(60,-22.802)$
$\odot_{2}(80,-24.716)$
$\odot_{3}(100,-16.087)$

FIGURe 2: Free space return loss.

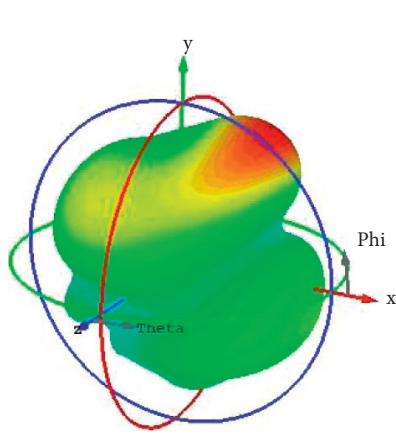

(a)
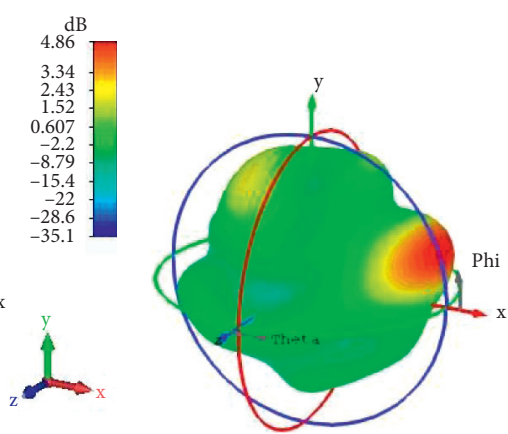

(b)
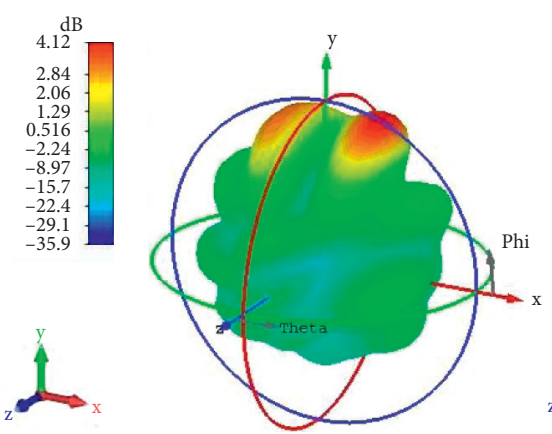

(c)

Figure 3: 3D radiation patterns at (a) $60 \mathrm{GHz}$, (b) $80 \mathrm{GHz}$, and (c) $100 \mathrm{GHz}$ (from left to right).

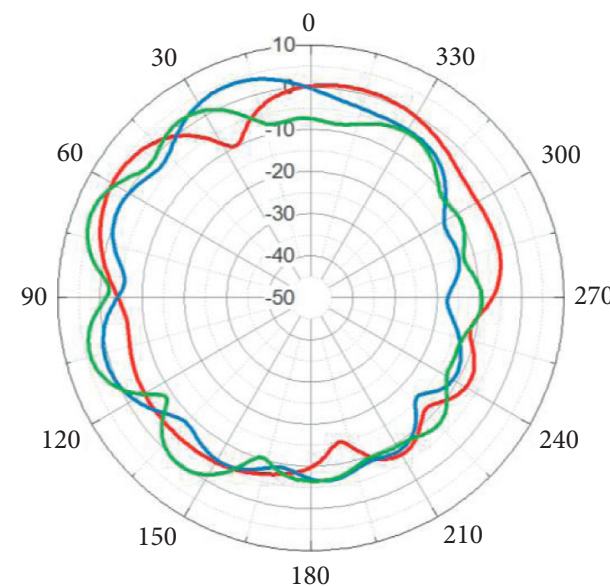

$-\quad 60 \mathrm{GHz}$
$-\quad 80 \mathrm{GHz}$
$-\quad 100 \mathrm{GHz}$

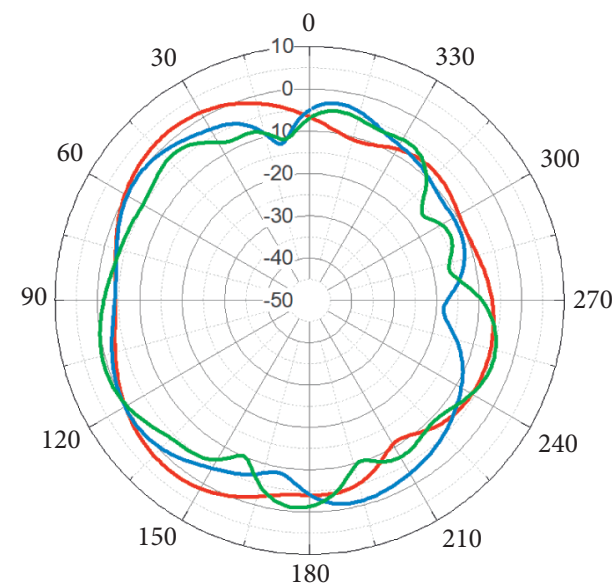

- $60 \mathrm{GHz}$

- $80 \mathrm{GHz}$

— $100 \mathrm{GHz}$

(a)

(b)

FIgURE 4: Polar plot radiation patterns of different planes: (a) XY-plane and (b) YZ-plane. 
$100 \mathrm{GHz}$, the main lobe directions are $58^{\circ}, 21^{\circ}$, and $69^{\circ}$, respectively. Lobe magnitudes were found at $4.33 \mathrm{~dB}$ for $60 \mathrm{GHz}$ with an angular width of 33.3 degrees, $4.11 \mathrm{~dB}$ for $80 \mathrm{GHz}$ with an angular width of 32.2 degrees, and $5.779 \mathrm{~dB}$ for $100 \mathrm{GHz}$ with an angular width of 21.1 degrees. Figure 4(b) shows the two-dimensional patterns for all three frequencies in the YZ-plane. For $60 \mathrm{GHz}, 80 \mathrm{GHz}$, and $100 \mathrm{GHz}$, the main lobe directions are at $140^{\circ}, 124^{\circ}$, and $109^{\circ}$, respectively. Lobe magnitudes were found at $1.97 \mathrm{~dB}$ for $60 \mathrm{GHz}$ with an angular width of 47.9 degrees, $0.365 \mathrm{~dB}$ for $80 \mathrm{GHz}$ with an angular width of 43.0 degrees, and $0.745 \mathrm{~dB}$ for $100 \mathrm{GHz}$ with an angular width of 42.1 degrees. The antenna shows stability at all three frequencies, though it provides better gain and directivity at $100 \mathrm{GHz}$. The XY- and YZ-plane radiation patterns for $60 \mathrm{GHz}$ and $80 \mathrm{GHz}$ are comparable, but at $100 \mathrm{GHz}$ they look slightly distorted.

3.3. VSWR. Figure 5 shows the free space voltage standing wave ratio curve over the frequency span of 50 to $110 \mathrm{GHz}$. Since the antenna has a wide bandwidth at $-10 \mathrm{~dB}$ return loss, it shows good impedance matching. Hence, the VSWR of the antenna over the wide frequency range shows good values. The voltage standing wave ratio (VSWR) values for three observing frequencies are 1.1564, 1.1234, and 1.3724 for $60 \mathrm{GHz}, 80 \mathrm{GHz}$, and $100 \mathrm{GHz}$, respectively. In comparison with these three selected frequencies $(60 \mathrm{GHz}$, $80 \mathrm{GHz}$, and $100 \mathrm{GHZ}$ ), the VSWR value is noticed to be slightly higher at $100 \mathrm{GHz}$.

3.4. Gain and Efficiency. Table 2 shows the values of gain, efficiency, and VSWR of three different frequencies of the antenna. From Table 2, it is observed that the antenna displays an overall better gain at $100 \mathrm{GHz}$ with $5.779 \mathrm{~dB}$. At $60 \mathrm{GHz}$, the gain is slightly lower than that of $100 \mathrm{GHz}$, but satisfactory. The gain in the E-band is a bit lower than the other two, but still above $4 \mathrm{~dB}$. In terms of efficiency, it shows that as the frequency increases, efficiency falls gradually. The higher radiation efficiency is noticed at $60 \mathrm{GHz}$ as compared with $100 \mathrm{GHz}$.

\section{On-Body Simulation}

A three-layer human body model was developed to test the antenna's on-body performance. For the convenience of the simulation, three outermost layers of the human body have been taken into account, which will be closer to the antenna. Skin, fat, and muscle are the three layers. A skin model with a skin thickness of $1.3 \mathrm{~mm}$ was created with its dielectric and other properties. Similarly, the fat layer is made with a thickness of $2 \mathrm{~mm}$, and the muscle layer, which is the inner and the heavier one, is made with a thickness of $10 \mathrm{~mm}$. The height and width of the whole human body model are $10 \mathrm{~mm} \times 14 \mathrm{~mm}$. All the layers are then placed sequentially without any gaps, like a real human body. Figures 6(a) and 6(b) show the created human body model with the antenna with its dimensions. The designed antenna was then placed over the human body model, keeping a distance of $4 \mathrm{~mm}$. After that, simulations were done, and then the newly simulated results were compared with the previous ones. The accounted properties (relative permittivity, loss tangent) [18] and dimensions of the three-layer human body model are shown in Table 3.

4.1. On-Body Return Loss. As illustrated in Figure 7, the onbody return loss curve is compared to the free space return loss. The return loss curve becomes more sharp-edged at the resonant locations and slightly left-shifted. On the observed frequencies of $60 \mathrm{GHz}, 80 \mathrm{GHz}$, and $100 \mathrm{GHz}$, return loss values decreased from $-22.8 \mathrm{~dB}$ to $-32.42 \mathrm{~dB},-24.72 \mathrm{~dB}$ to $-25.64 \mathrm{~dB}$, and $-16.09 \mathrm{~dB}$ to $-17.43 \mathrm{~dB}$, respectively. However, this antenna shows good return loss responses both in free space and also on the body. Both free space and on-body return loss levels are less than $-10 \mathrm{~dB}$ at $60 \mathrm{GHz}, 80 \mathrm{GHz}$, and $100 \mathrm{GHz}$. If we consider bandwidth at $-10 \mathrm{~dB}$, this antenna shows super wideband impedance bandwidth, which is very good for very high-speed data transmission. Because of the presence of the human body, there are negligible effects on the on-body return loss for this proposed super wideband mmWave antenna in this research work.

4.2. 3D Radiation Free Space and On-Body Radiation Pattern Comparison. The comparison of free space and on-body $3 \mathrm{D}$ radiation patterns for $60 \mathrm{GHz}, 80 \mathrm{GHz}$, and $100 \mathrm{GHz}$ is shown in Figures 8(a)-8(f). From Figure 8, it is noted that there are very slight changes in on-body $3 \mathrm{D}$ radiation patterns in comparison with the on-body case. However, due to the presence of the human body model at the back of the antenna, the peak gain for on-body cases increases for all three frequencies. At $60 \mathrm{GHz}$ and $80 \mathrm{GHz}$, passive lobes are detected with the existing ones with a very slight change in directivity, except for $100 \mathrm{GHz}$, which remains very stable. Gain increased in all three frequencies while it is close to the human body model. For $60 \mathrm{GHz}$, it has now increased to $5.39 \mathrm{~dB}$ from $4.86 \mathrm{~dB}$. Similarly, for $80 \mathrm{GHz}$, it has shifted to $4.69 \mathrm{~dB}$ from $4.12 \mathrm{~dB}$, and for $100 \mathrm{GHz}$, it recorded $7.01 \mathrm{~dB}$ from $6.54 \mathrm{~dB}$.

4.3. Comparison of Free Space and On-Body Polar Plot Radiation Patterns. Figures 9(a)-9(f) illustrate a comparison of polar plot free space and on-body radiation patterns for the XY- and YZ-planes at $60 \mathrm{GHz}, 80 \mathrm{GHz}$, and $100 \mathrm{GHz}$. It is noted that in both planes, the radiation patterns do not change much but the power level does. Figure 9 present the radiation pattern changes after placing the antenna $4 \mathrm{~mm}$ apart from the human body on two different planes at $60 \mathrm{GHz}, 80 \mathrm{GHz}$, and $100 \mathrm{GHz}$. Three figures from the top row of the XY-plane show the changes are very slight in the patterns for all three frequencies. The main lobe and side lobe directions are almost identical except for some gain value changes. After placing the antenna close to the human body model, on the XY-plane, at 60,80 , and $100 \mathrm{GHz}$, the main lobe magnitudes are now $5.13 \mathrm{~dB}, 4.71 \mathrm{~dB}$, and $7.01 \mathrm{~dB}$, respectively. The primary lobe directions are $58^{\circ}, 21^{\circ}$, and $70^{\circ}$ in the same order. Similarly, 


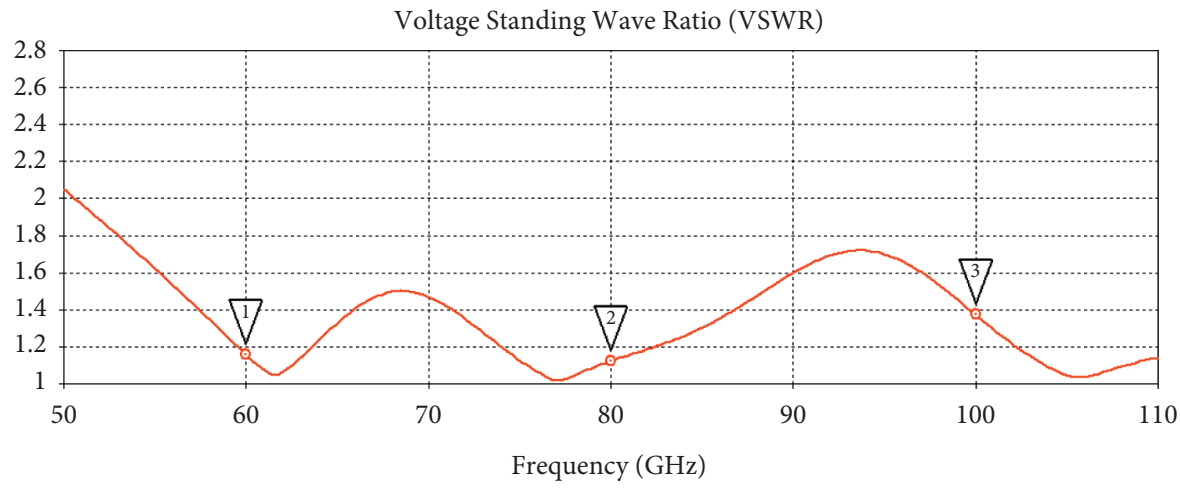

$\odot_{1}(60,1.1564)$
$\odot_{2}(80,1.1234)$
$\odot_{3}(100,1.3724)$

FIGURE 5: Free space voltage standing wave ratio curve.

TABLE 2: Gain and radiation efficiency.

\begin{tabular}{lccc}
\hline Frequencies & $60 \mathrm{GHz}$ & $80 \mathrm{GHz}$ & $100 \mathrm{GHz}$ \\
\hline Radiation efficiency (\%) & 70.65 & 63.96 & 57.31 \\
Total efficiency (\%) & 70.28 & 63.74 & 55.89 \\
VSWR & 1.1564 & 1.1234 & 1.3724 \\
Gain (dB) & 4.669 & 4.125 & 5.779 \\
\hline
\end{tabular}
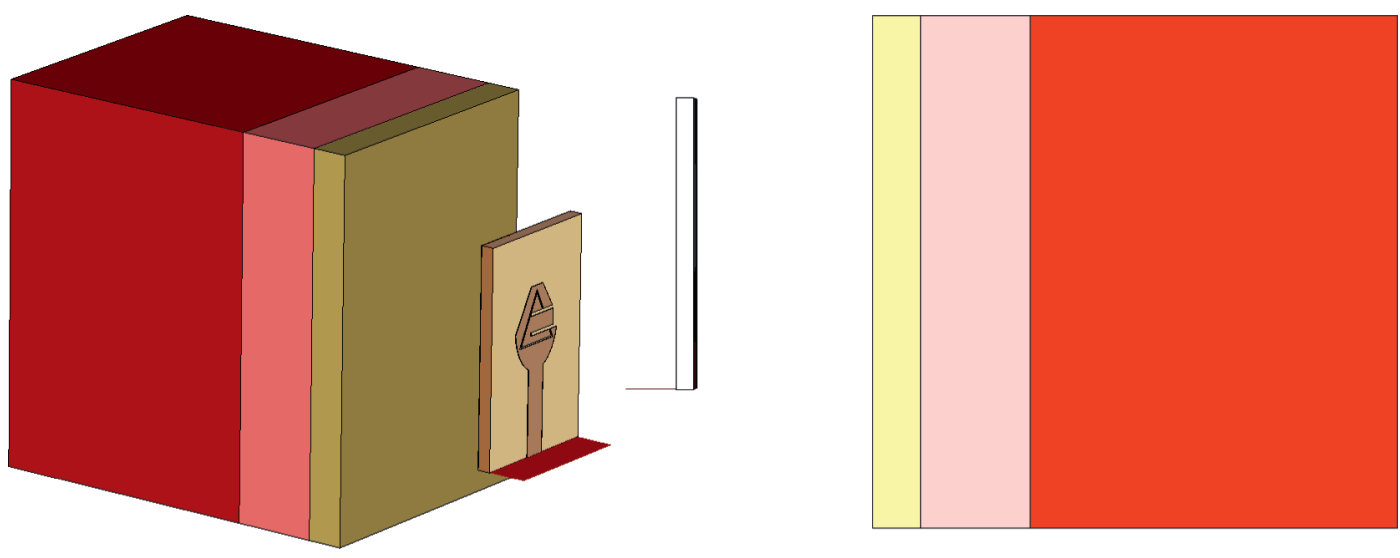

3D View

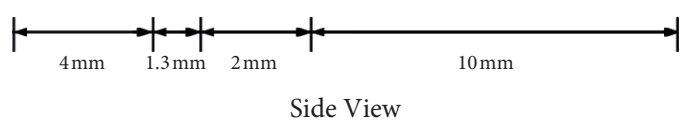

(a)

(b)

Figure 6: Antenna with human body model: (a) 3D view and (b) side view.

TABLE 3: Modeled human body layer parameters and properties.

\begin{tabular}{lccc}
\hline Layers & Skin & Fat & \\
Length $(\mathrm{mm})$ & 14 & 14 & Muscle \\
Width $(\mathrm{mm})$ & 10 & 10 & 14 \\
Thickness $(\mathrm{mm})$ & 1.3 & 2 & 10 \\
Ave. penetration depth $(\mathrm{mm})$ & 0.48 & 3.37 & 10 \\
Relative permittivity & 7.9753 & 3.1324 & 0.41 \\
Loss tangent & 1.37 & 0.27 & 2.8152 \\
Conductivity $(\mathrm{S} / \mathrm{m})$ & 36.397 & 2.8152 & 0.0012 \\
\hline
\end{tabular}




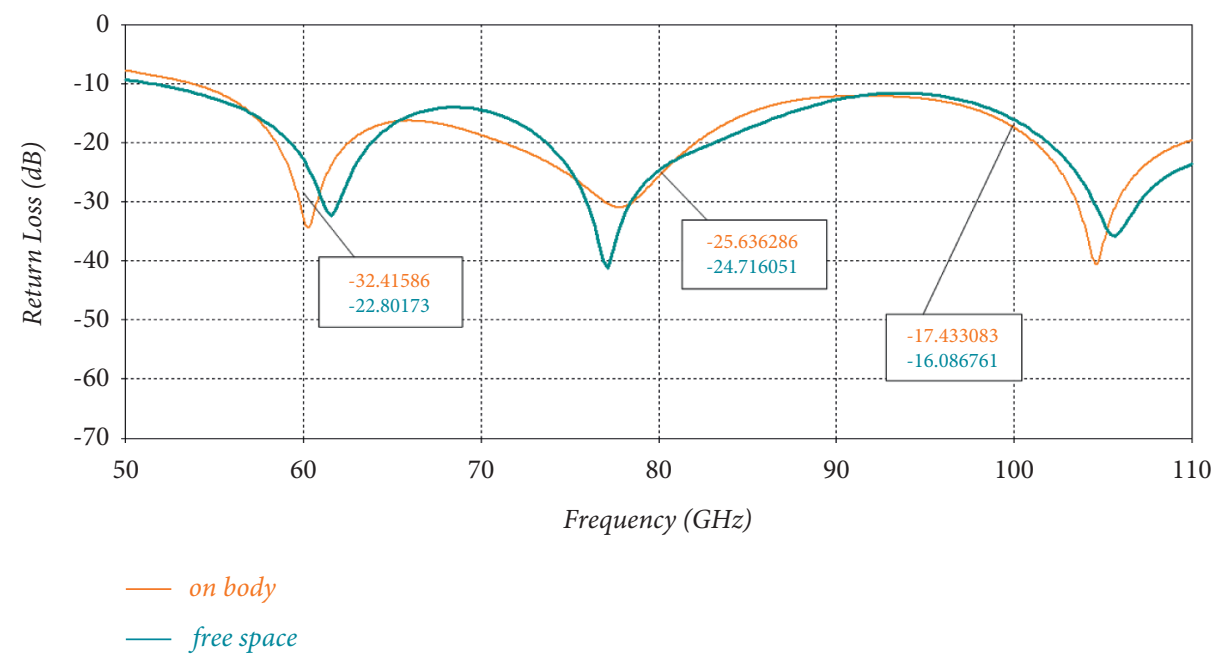

Figure 7: Comparison curves for free space and on-body return loss.

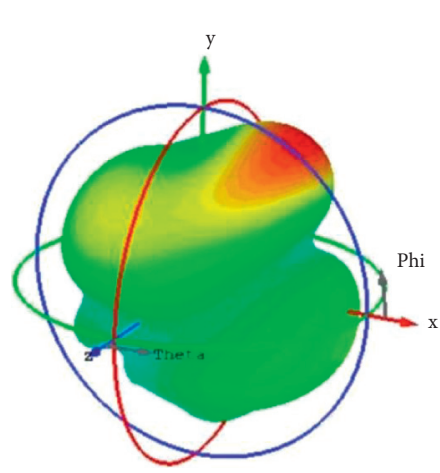

(a)

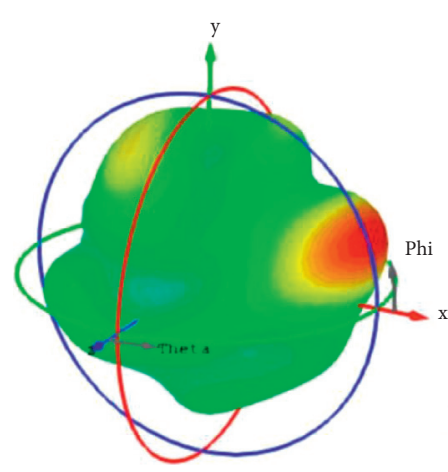

(c)
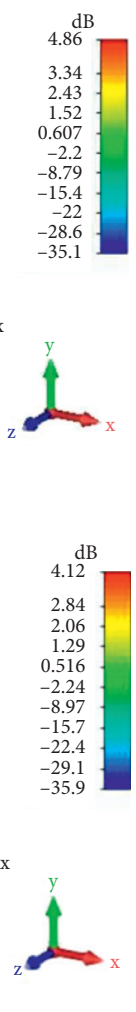

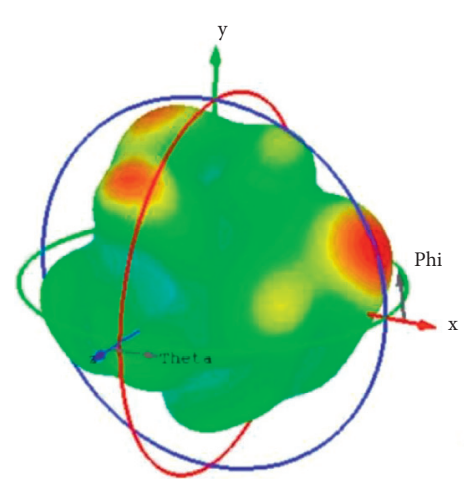

(d)
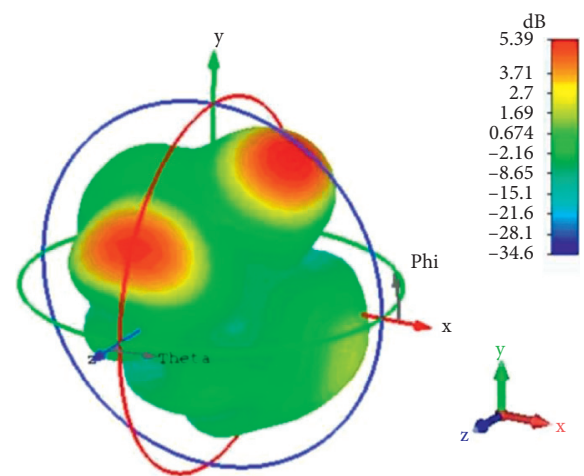

(b)

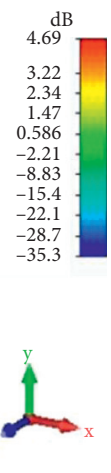

)

FIgURE 8: Continued. 


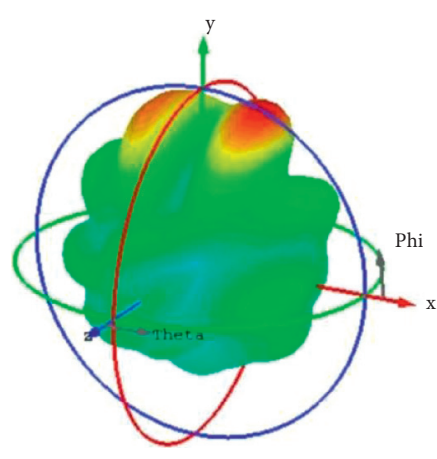

(e)
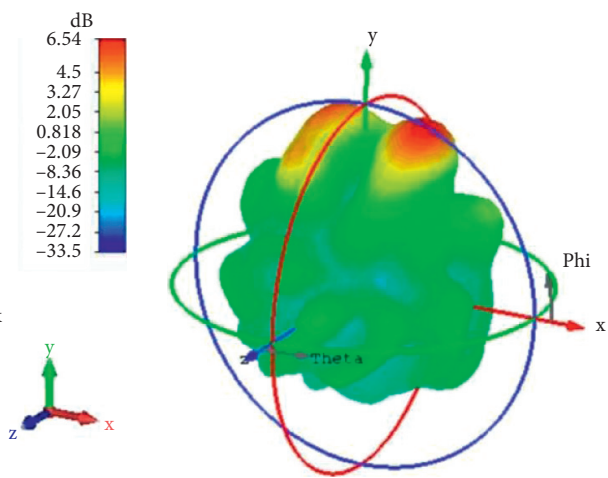

(f)

FiguRe 8: : 3D radiation pattern comparison: (a) free space $60 \mathrm{GHz}$, (b) on-body $60 \mathrm{GHz}$, (c) free space at $80 \mathrm{GHz}$, (d) on-body at $80 \mathrm{GHz}$, (e) free space at $100 \mathrm{GHz}$, and (f) on-body at $100 \mathrm{GHz}$.

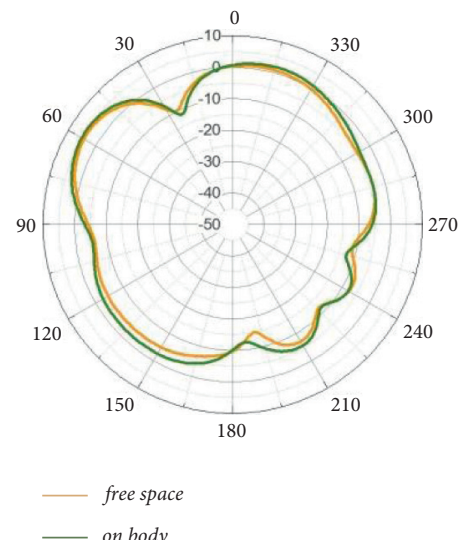

(a)

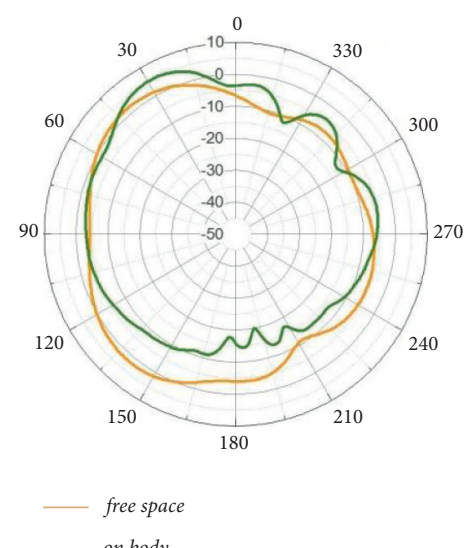

(d)

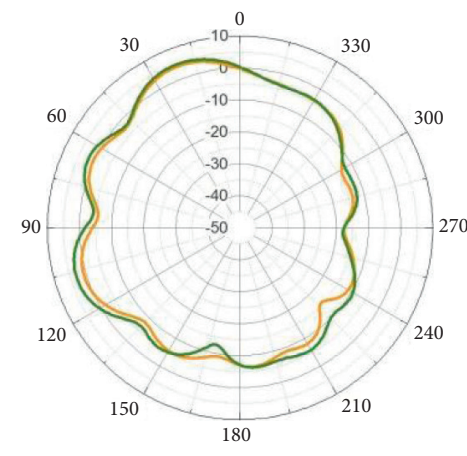

- free space

_ on body

(b)

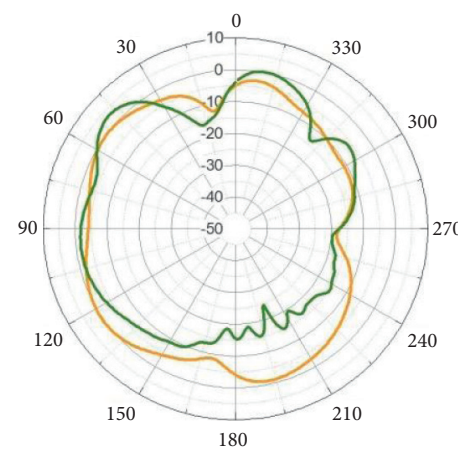

free space
- on body

(e)

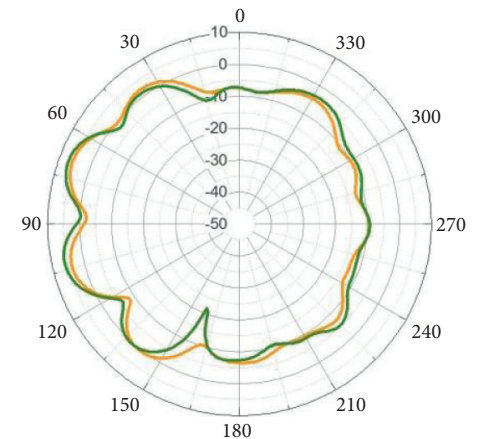

- free space

— on body

(c)

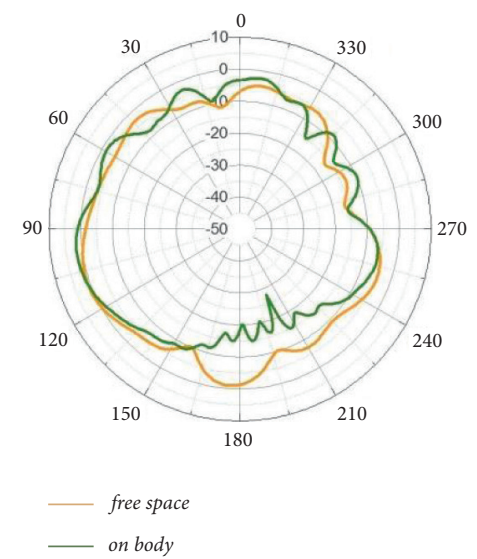

(f)

FIGURE 9: Free space versus on-body radiation pattern comparison: (a) XY-plane at $60 \mathrm{GHz}$, (b) XY-plane at $80 \mathrm{GHz}$, (c) XY-plane at $100 \mathrm{GHz},(\mathrm{d}) \mathrm{YZ}$-plane at $60 \mathrm{GHz}$, (e) YZ-plane at $80 \mathrm{GHz}$, and (f) YZ-plane at $100 \mathrm{GHz}$.

for 60,80 , and $100 \mathrm{GHz}$ on the YZ-plane, the main lobe magnitudes are now $5.12 \mathrm{~dB}, 3.16 \mathrm{~dB}$, and $1.75 \mathrm{~dB}$ with their primary lobe directions of $29^{\circ}, 48^{\circ}$, and $99^{\circ}$, respectively. To have a clear view of the changes and compare them with the free space data, Table 4 has been presented.
From Table 4, it is determined that the antenna performs much better when it is closer to the human body from a radiation perspective. The results on the XY-plane are very stable in both free space and on-body conditions. Only some variations in gain and directivity can be 
TABLE 4: Comparison of polar plot radiation patterns at different angles: lobe-wise (FS, free space and OB, on-body).

\begin{tabular}{|c|c|c|c|c|c|c|c|c|c|c|c|c|}
\hline \multirow{3}{*}{ Frequency and planes } & \multicolumn{4}{|c|}{$60 \mathrm{GHz}$} & \multicolumn{4}{|c|}{$80 \mathrm{GHz}$} & \multicolumn{4}{|c|}{$100 \mathrm{GHz}$} \\
\hline & \multicolumn{2}{|c|}{$\mathrm{XY}$} & \multicolumn{2}{|c|}{$\mathrm{YZ}$} & \multicolumn{2}{|c|}{$\mathrm{XY}$} & \multicolumn{2}{|c|}{$\mathrm{YZ}$} & \multicolumn{2}{|c|}{$\mathrm{XY}$} & \multicolumn{2}{|c|}{$\mathrm{YZ}$} \\
\hline & FS & $\mathrm{OB}$ & FS & $\mathrm{OB}$ & FS & $\mathrm{OB}$ & FS & $\mathrm{OB}$ & FS & OB & FS & $\mathrm{OB}$ \\
\hline Primary lobe magnitude $(\mathrm{dB})$ & 4.33 & 5.13 & 1.97 & 5.12 & 4.11 & 4.71 & 0.37 & 3.16 & 5.77 & 7.01 & 0.75 & 1.75 \\
\hline Primary lobe direction & $58^{\circ}$ & $58^{\circ}$ & $140^{\circ}$ & $29^{\circ}$ & $21^{\circ}$ & $21^{\circ}$ & $124^{\circ}$ & $48^{\circ}$ & $69^{\circ}$ & $70^{\circ}$ & $109^{\circ}$ & $99^{\circ}$ \\
\hline Lobe width (degree) & 33.3 & 34.8 & 47.9 & 30.2 & 32.2 & 33.2 & 43 & 21.9 & 21.1 & 19.7 & 42.1 & 36.4 \\
\hline Side lobe level (dB) & -3.5 & -3.2 & -5.9 & -6.8 & -3.3 & -1.5 & -1.5 & -3.0 & -1.7 & -1.0 & -1.7 & -3.2 \\
\hline
\end{tabular}

noticed on the H-plane (YZ). It needs to be mentioned that the table data for "primary lobe magnitude" is rounded up to two decimal places, while others are rounded up to one.

4.4. On-Body versus Free Space VSWR Comparison. After placing the antenna $4 \mathrm{~mm}$ above the created human body model, the VSWR curve was calculated again and compared with the previously generated "free space" curve. Figure 10 shows the comparison of free pace and on-body VSWR curves. The on-body VSWR curve pattern is nearly similar to the free space one, but the on-body curve is noticed to be slightly left-shifted. For the three observing frequencies, results have become much better for $60 \mathrm{GHz}$, which is down to 1.049 from 1.156 now. At $80 \mathrm{GHz}$, both free space and the body curve get intertwined, and values are very close. At $100 \mathrm{GHz}$, it is 1.31 , which is better than the 1.37 for free space.

4.5. Gain, VSWR, and Efficiency Comparison. In Table 5, onbody simulated gain, VSWR, and efficiency results were compared with the previously recorded free space simulation data. Due to the lossy nature of the human body, efficiencies are reduced for on-body scenarios. Lossy tissues of the human body absorb radiation power, which results in a reduction of efficiency from the free space when an antenna is placed on the body. Almost $8 \%$ of radiation efficiency is reduced at all three frequencies, which indicates that the gradual increment of frequencies alongside the gradual decrease in efficiency does not have a proportional effect on the antennas surrounding the human body. Voltage standing wave ratio at $60 \mathrm{GHz}$ looks more revised in on-body simulation. In terms of gain, on-body performance data outpaced free space performance in all three frequencies. For all three frequencies $(60 \mathrm{GHz}$, $80 \mathrm{GHz}$, and $100 \mathrm{GHz}$ ), the gain increases when the antenna is placed on the body. However, at a higher frequency, at $100 \mathrm{GHz}$, the on-body gain is noticed to be the highest $(7.007 \mathrm{~dB})$.

All the designs and the results in this study are based on computer simulation using professional simulation software, CST Microwave Studio. Unfortunately, these simulated results could not be verified with a real-life fabricated one for lack of scope. However, many published articles have justified their CST Microwave Studio simulated results with real-life measurements and found similar outcomes [19-22].

\section{Distance-Based Study}

To have a clear concept of the effects of the presence of the human body in close proximity to the antenna clearly, a distance-based study was conducted. The antenna was positioned at five different distances from the human body model in this investigation, and the return loss, radiation patterns, and other variables were simulated to see how they were influenced. The results are achieved by placing the antenna $0 \mathrm{~mm}$ (close contact), $2 \mathrm{~mm}, 4 \mathrm{~mm}, 6 \mathrm{~mm}$, and finally $8 \mathrm{~mm}$ apart from the human body and comparing with free space data. This section is based on the distance-based analysis of those results to understand the characteristics of the proposed super wideband mmWave antenna more precisely.

5.1. Return Loss. The antenna's simulated return loss curves at five various distances from the human body model with a free space return loss curve are shown in Figure 11. The green curve with triangular marks represents the return loss of $0 \mathrm{~mm}$ and is clearly distinguishable from others. It is observed that when the antenna is placed directly on the body, the return loss graph changes dramatically as compared to the free space one. As the antenna is taken $2 \mathrm{~mm}$ or more away from the human body, the return loss curve becomes nearly stable. For $6 \mathrm{~mm}$ and $8 \mathrm{~mm}$ distances, the impact of the human body on the antenna's return loss curve is very low. The major shape shifting of return loss is done from a distance of $0 \mathrm{~mm}$ to $2 \mathrm{~mm}$. It is clear that the variation in the antenna distance from the human body model has an effect on the return loss for this super wide band compact antenna. When the antenna is very close to the body, the effect is stronger, and when it is farther away, the effect is weaker. However, the return loss values for $60 \mathrm{GHz}, 80 \mathrm{GHz}$, and $100 \mathrm{GHz}$ are all less than $-10 \mathrm{~dB}$ in all circumstances.

5.2. Radiation Patterns of Different Planes. In Figures 12(a)-12(f), the polar plot radiation patterns of this antenna are shown in the XY- and XZ-planes for three different frequencies $(60 \mathrm{GHz}, 80 \mathrm{GHz}$, and $100 \mathrm{GHz})$ while the antenna was placed at five different distances $(0 \mathrm{~mm}$, $2 \mathrm{~mm}, 4 \mathrm{~mm}, 6 \mathrm{~mm}$, and $8 \mathrm{~mm})$. In these graphs of Figures 12(a)-12(f), the free space polar plot radiation patterns are also included for comparison purposes. The radiation pattern is substantially altered, while the antenna is situated $0 \mathrm{~mm}$ away from the body, as seen in Figures 12(a)$12(\mathrm{c})$ in the XY-plane. The main lobe magnitudes at $60 \mathrm{GHz}$, 


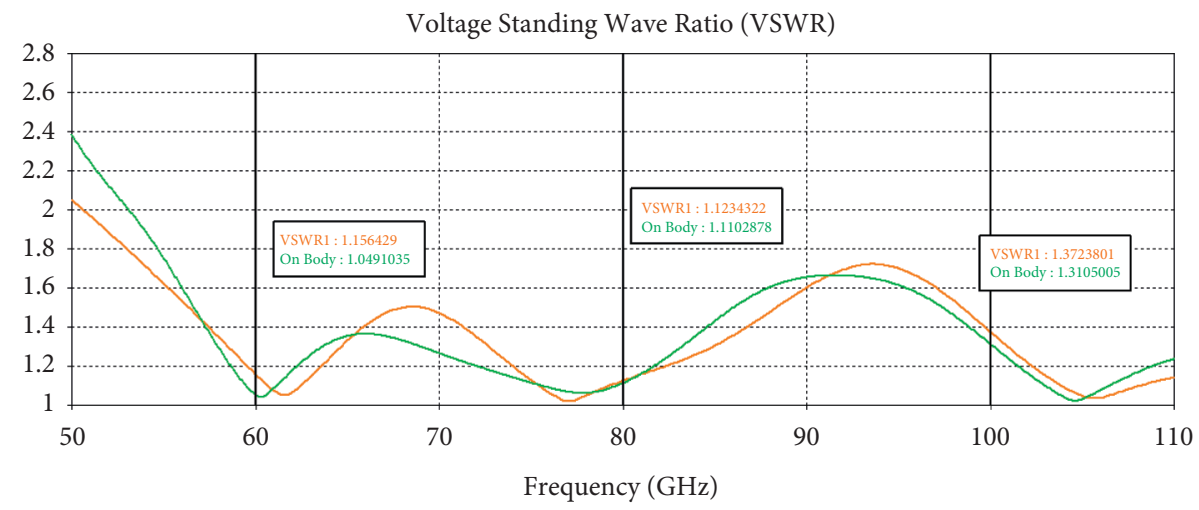

- free space
- on body

FIGURE 10: Free space versus on-body VSWR curves.

TABLE 5: Gain, VSWR, and efficiency comparison (FS = free space and $\mathrm{OB}=$ on-body).

\begin{tabular}{lcccccc}
\hline \multirow{2}{*}{ Frequencies } & \multicolumn{2}{c}{$60 \mathrm{GHz}$} & \multicolumn{2}{c}{$80 \mathrm{GHz}$} & \multicolumn{2}{c}{$100 \mathrm{GHz}$} \\
& FS & OB & FS & OB & FS \\
\hline Radiation efficiency (\%) & 70.65 & 62.12 & 63.96 & 53.55 & 57.31 & 49.61 \\
Total efficiency (\%) & 70.28 & 62.08 & 63.74 & 53.25 & 55.89 & 48.71 \\
VSWR & 1.1564 & 1.0491 & 1.1234 & 1.1103 & 1.3724 & 1.3105 \\
Gain (dB) & 4.669 & 5.394 & 4.125 & 4.688 & 5.779 & 7.007 \\
\hline
\end{tabular}

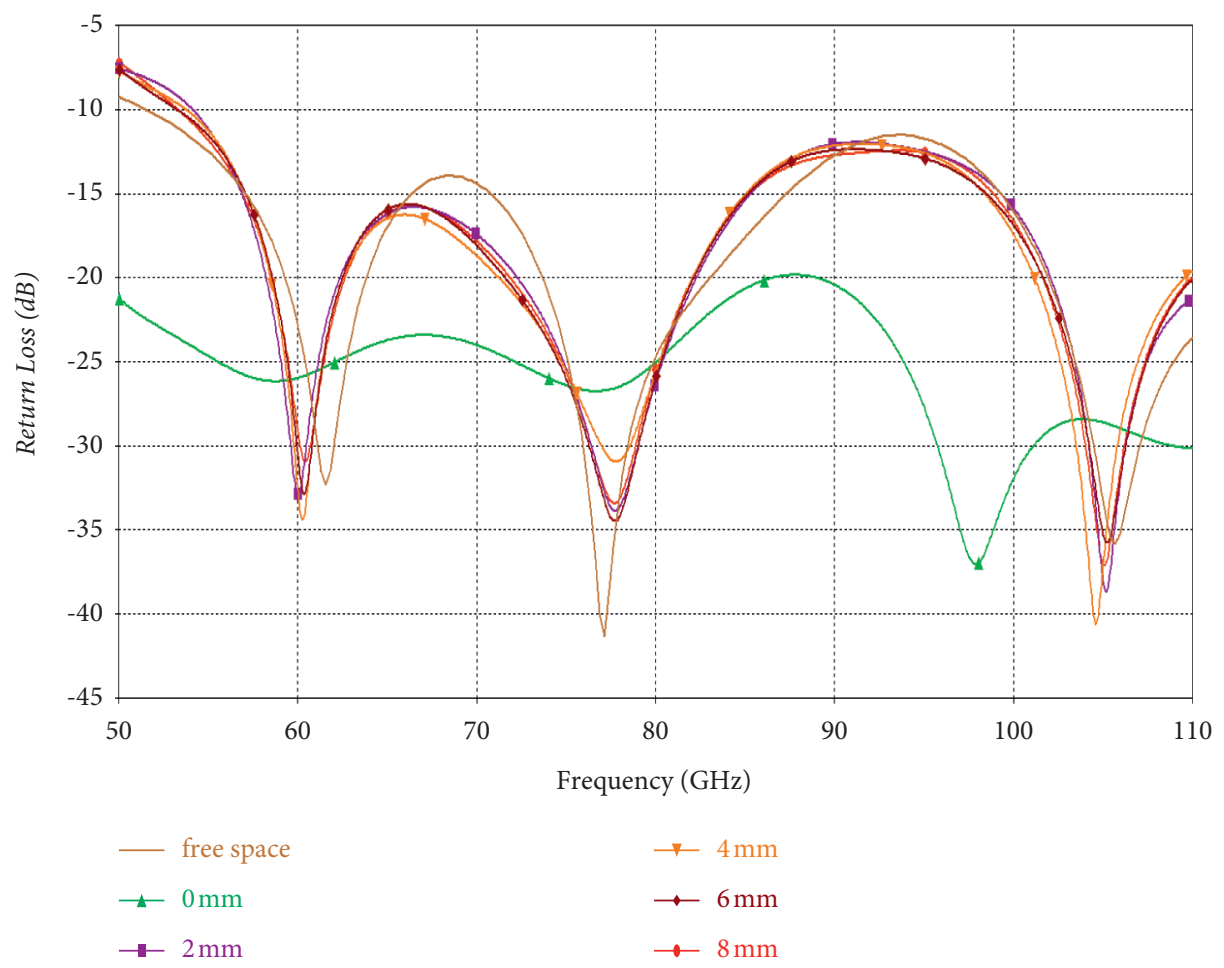

FIgURE 11: Return loss from the human body model and free space at various distances.

$80 \mathrm{GHz}$, and $100 \mathrm{GHz}$ are $-11.2 \mathrm{~dB},-12 \mathrm{~dB}$, and $-12.5 \mathrm{~dB}$, respectively. In this case, the radiation for both planes does not change much due to the close proximity of the human body, but the power level is reduced. It is not ideal to place the antenna on the body directly. In real-life scenarios, the antenna with the wearable sensor and system will be on the 


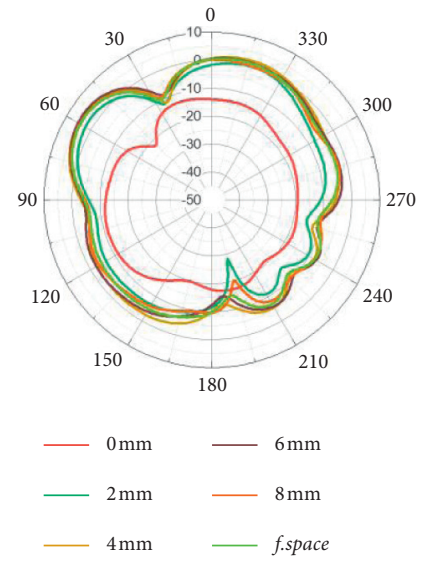

(a)
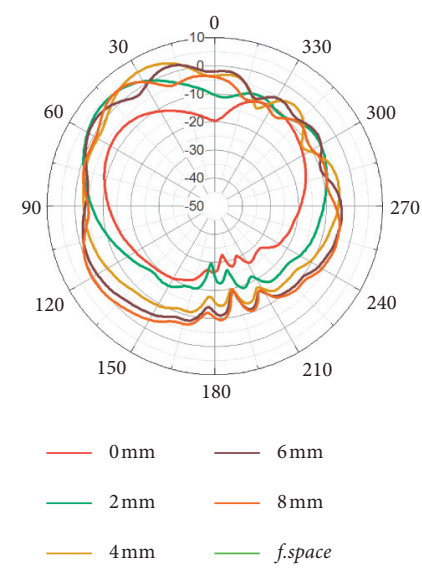

(d)
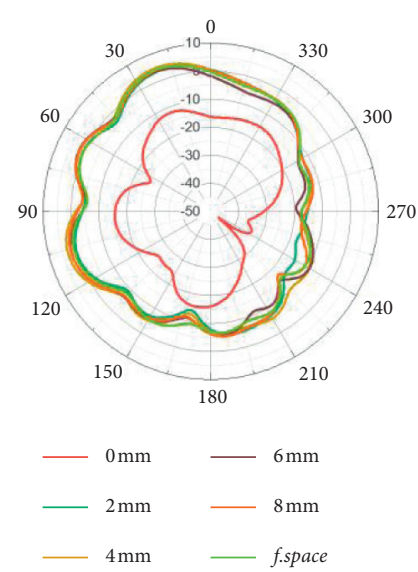

(b)

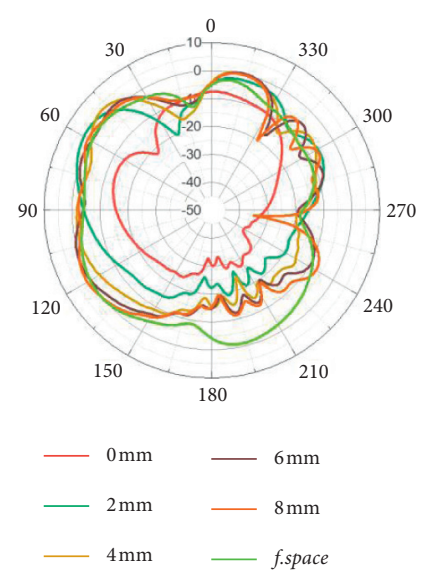

(e)
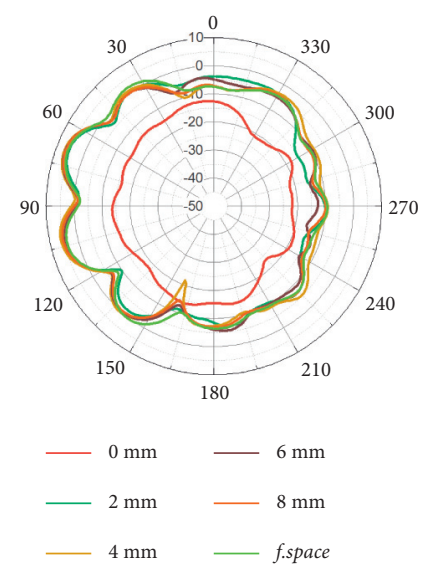

(c)
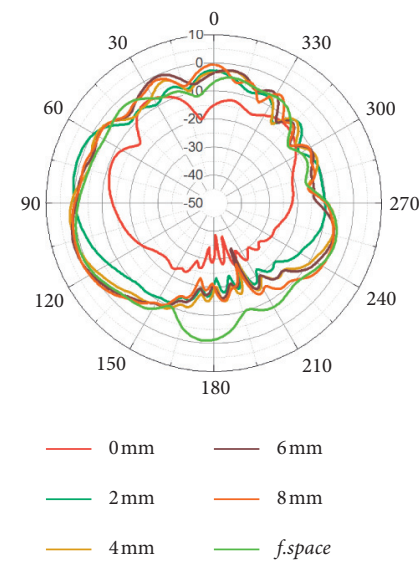

(f)

Figure 12: Polar plot antenna radiation patterns in the XY-plane at (a) $60 \mathrm{GHz}$, (b) $80 \mathrm{GHz}$, and (c) $100 \mathrm{GHz}$ form different distances. Polar plot radiation patterns on YZ-plane at (d) $60 \mathrm{GHz}$, (e) $80 \mathrm{GHz}$, and (f) $100 \mathrm{GHz}$ from different distances.

dress of the human body. For $2 \mathrm{~mm}$ and above distances, the radiation patterns do not change too much. Similarly, in the YZ-plane, radiation patterns are quite distinguishable at a distance of $0 \mathrm{~mm}$ rather than at any other distance of $2 \mathrm{~mm}$ or more. It shows a similar trend. However, the figure distorts a little abruptly at particular angles in the YZ-plane at higher frequencies as the distance varies. From this distance variation on-body parametric study, it is noted that even at $2 \mathrm{~mm}$ distance, the antenna on the body performs well in terms of XY and YZ radiation patterns, and at this distance, acceptable radiation is noticed. The power level of the radiation patterns is reported to be the lowest at $0 \mathrm{~mm}$ in all circumstances (antenna direct on the body).

5.3. VSWR from Different Distances. Figure 13 depicts the antenna VSWR at various gaps from the human body model. The free space VSWR of this antenna has also been included for comparison purposes. The green line with a triangular mark indicates the voltage standing wave ratio at a $0 \mathrm{~mm}$ distance from the human body model. As in the previous results, the VSWR curve also shows that the $0 \mathrm{~mm}$ distance curve stands separately from the others, which are 1.1, 1.12, and 1.05 at $60 \mathrm{GHz}, 80 \mathrm{GHz}$, and $100 \mathrm{GHz}$, respectively. The rest of the curves overlap at several frequencies on the path and fluctuate between 1.02 and 1.66 after $60 \mathrm{GHz}$.

5.4. Investigation of Efficiency and Gain. Table 6 shows the radiation efficiency, total efficiency, and gain comparison of the antenna at three preselected frequencies $(60 \mathrm{GHz}$, $80 \mathrm{GHz}$, and $100 \mathrm{GHz}$ ). In Table 6 , results of free space, $0 \mathrm{~mm}, 2 \mathrm{~mm}, 4 \mathrm{~mm}, 6 \mathrm{~mm}$, and $8 \mathrm{~mm}$, are presented. In the previous calculation of this antenna and this table, it is clearly visible that antenna performance is highly influenced when it is directly in contact with the human body. At $0 \mathrm{~mm}$ distance, efficiency falls from 4.96 to 4.4 at $60 \mathrm{GHz}$ to $100 \mathrm{GHz}$. Nevertheless, even just a couple of millimeters away, the performance stays very stable. Therefore, the ideal distance to place this proposed antenna on the body is considered to be $2 \mathrm{~mm}$ away from the body. At $2 \mathrm{~mm}$ distance from the human body, this antenna performs very well, and the performance parameters are very much at an acceptable level. However, other distances can also be considered. Here, we have commented on the lowest minimum gap from the body to get an acceptable level of performance. At $2 \mathrm{~mm}$ distance, this antenna shows $56 \%$ radiation efficiency at $60 \mathrm{GHz}$, and at the same distance, this 


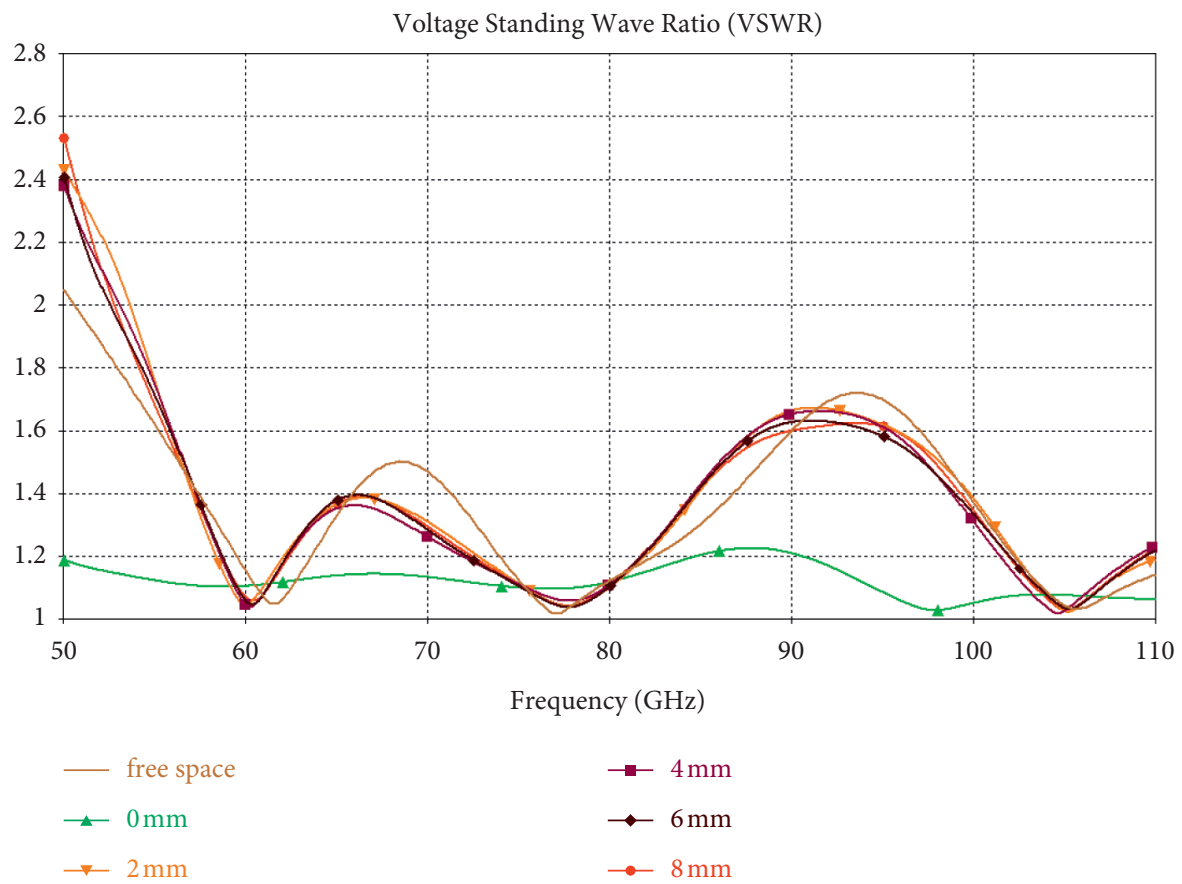

FIGURE 13: VSWR at various distances from the human body and in free space.

TABLE 6: Gain and efficiency comparison.

\begin{tabular}{|c|c|c|c|c|c|c|c|}
\hline \multicolumn{2}{|c|}{$\begin{array}{c}\text { Distances } \\
\text { Frequency }(\mathrm{GHz})\end{array}$} & Free space & $0 \mathrm{~mm}$ & $2 \mathrm{~mm}$ & $4 \mathrm{~mm}$ & $6 \mathrm{~mm}$ & $8 \mathrm{~mm}$ \\
\hline \multirow{4}{*}{ Radiation efficiency (\%) } & 60 & 70.65 & 4.966 & 56 & 62.12 & 65.91 & 68.6 \\
\hline & 80 & 63.96 & 4.94 & 47.49 & 53.55 & 58.52 & 60.44 \\
\hline & 100 & 57.31 & 4.404 & 41.28 & 49.61 & 52.75 & 53.8 \\
\hline & 60 & 70.28 & 4.953 & 55.97 & 62.08 & 65.85 & 68.51 \\
\hline \multirow[t]{2}{*}{ Total efficiency (\%) } & 80 & 63.74 & 4.924 & 47.37 & 53.25 & 58.38 & 60.28 \\
\hline & 100 & 55.89 & 4.401 & 40.21 & 48.71 & 51.67 & 52.63 \\
\hline \multirow{3}{*}{ Gain $(\mathrm{dB})$} & 60 & 4.669 & -6.368 & 6.071 & 5.394 & 5.463 & 5.407 \\
\hline & 80 & 4.125 & -4.665 & 5.413 & 4.688 & 4.253 & 4.018 \\
\hline & 100 & 5.779 & -6.524 & 6.853 & 7.007 & 6.852 & 6.511 \\
\hline
\end{tabular}

antenna shows nearly $6.85 \mathrm{~dB}$ gain at $100 \mathrm{GHz}$. Even when it is quite close to the body, this antenna produces interesting results. As the distance between the body and the antenna extends, the performance improves.

\section{Conclusion}

In this paper, a novel and very tiny design of a multiple band super wide band millimeter wave antenna is presented. Simulations were done with the newly designed antenna in both free space and the human body with the help of modeling human body structures. The results were analyzed and compared. Simulations were done at three different frequencies of the mmWave spectrum (EHF range) and found promising results. The notable part was that the design is less vulnerable to the presence of the lossy human body, which makes it suitable and a potential candidate for body-centric communications. With a volume of $8 \mathrm{~mm} \times 5.12 \mathrm{~mm} \times 1.57 \mathrm{~mm}$, the antenna is very small. Due to its very tiny size and printed structure, it can be equipped with other lightweight, portable devices or can be placed on a human body. Moreover, multiple band operability made the antenna unique and widened its possibilities and area of application. The proposed antenna has a super wideband impedance bandwidth, which will be an excellent candidate for high data rate applications. According to the knowledge of the authors of this paper, this antenna achieved the most wideband bandwidth as it works over a large frequency spectrum with a return loss of less than $-10 \mathrm{~dB}$. This antenna is the smallest mmWave antenna so far found in the open literature. This proposed antenna design and study in this paper is a novel work in mmWave antennas.

Further distance-based study clarifies the antenna's indepth nature, which helped determine where and how it could serve in body-centric communications. We know the body area network (BAN) or BCN consists of three types of communication: in-body, off-body, and on-body communications [7]. When the sensor is implanted in the body and made to communicate with the external module, it is known as in-body communication. When the communication 
device is placed on the human body (contact or contactless close proximity, e.g., $2 \mathrm{~mm}$; can be of a thread or fabric thickness) and set to communicate with similar on-body sensors, it is known as on-body communication. If one of them is set outside the body to transfer and receive data, it is known as "off-body communication." From the final distance-based analysis, it can be said that the performance of this proposed antenna is mostly suitable for on-body communications in body-centric networks (BCNs). In the future, this antenna could be designed on a textile substrate. In addition, the bending performance of the antenna can be investigated.

\section{Data Availability}

The data used to support the findings of this study are freely available at http://niremf.ifac.cnr.it/tissprop/.

\section{Conflicts of Interest}

The authors declare that they have no conflicts of interest regarding the present study.

\section{Acknowledgments}

The authors are thankful for the support from Taif University Researchers Supporting Project (TURSP-2020/98), Taif University, Taif, Saudi Arabia.

\section{References}

[1] N. Guo, R. C. Qiu, S. S. Mo, and K. Takahashi, "60-GHz millimeter-wave radio: principle, technology, and new results," EURASIP Journal on Wireless Communications and Networking, vol. 2007, no. 1, p. 190, 2007.

[2] D. Dawson, Unlicensed Millimeter Wave Spectrum, CircleID, Online]. Available: https://www.circleid.com/posts/ 20190918_unlicensed_millimeter_wave_spectrum/, 2019.

[3] inFCC Report, https://fcc.report/IBFS/SAT-LOA-2020052600055/2378669, 2021.

[4] A. A. Thabit, M. S. Mahmoud, A. Alkhayyat, and Q. H. Abbasi, "Energy harvesting internet of things healthbased paradigm: towards outage probability reduction through inter-wireless body area network cooperation," International Journal of Distributed Sensor Networks, vol. 15, no. 10, pp. 1-12, 2019.

[5] P. S. Hall and Y. Hao, "Antennas and propagation for body centric communications," in Proceedings of the First European Conference On Antennas and Propagation, pp. 1-7, Nice, France, 2006.

[6] T.-W. Koo, Y.-J. Hong, G.-k. Park, K. Shin, and J.-G. Yook, "Extremely low-profile antenna for attachable bio-sensors," IEEE Transactions on Antennas and Propagation, vol. 63, no. 4, pp. 1537-1545, 2015.

[7] P. S. Hall and Y. Hao, Antennas and Propagation for BodyCentric Wireless Communications, Artech House, Norwood, MA, USA, 2006.

[8] A. Christ, A. Klingenbock, T. Samaras, C. Goiceanu, and N. Kuster, "The dependence of electromagnetic far-field absorption on body tissue composition in the frequency range from $300 \mathrm{MHz}$ to $6 \mathrm{GHz}$," IEEE Transactions on Microwave Theory and Techniques, vol. 54, no. 5, pp. 2188-2195, 2006.
[9] C. Calvez, R. Pilard, C. Person et al., "Millimeter-wave antenna designs for $60 \mathrm{GHz}$ applications: $\mathrm{SoC}$ and $\mathrm{SiP}$ approaches," International Journal of Microwave and Wireless Technologies, vol. 3, no. 2, pp. 179-188, 2011.

[10] J. Adamu, "Millimeter wave patch antenna design antenna for future 5G applications," International Journal of Engineering and Technical Research, vol. 6, pp. 289-291, 2017.

[11] J. Choi, J. Choi, and W. Hwang, "Miniature millimeter-wave $5 \mathrm{G}$ antenna fabricated using anodized aluminum oxide for mobile devices," ACS Omega, vol. 5, no. 40, 2020.

[12] C.-N. Hu, D.-C. Chang, C.-H. Yu, T.-W. Hsaio, and D.-P. Lin, "Millimeter-wave microstrip antenna array design and an adaptive algorithm for future $5 \mathrm{G}$ wireless communication systems," International Journal of Antennas and Propagation, vol. 2016, Article ID 7202143, 10 pages, 2016.

[13] H. Shawkey and D. Elsheakh, "Multiband dual-meander line antenna for body-centric networks' biomedical applications by using UMC $180 \mathrm{~nm}$," Electronics, vol. 9, p. 1350, 2020.

[14] N. Chahat, M. Zhadobov, S. A. Muhammad, L. Le Coq, and R. Sauleau, "60-GHz textile antenna array for body-centric communications," IEEE Transactions on Antennas and Propagation, vol. 61, no. 4, pp. 1816-1824, 2013.

[15] M. Monirujjaman Khan, K. Islam, M. N. A. Shovon, M. Masud, M. Baz, and M. A. AlZain, "Various textiles-based comparative analysis of a millimeter wave miniaturized novel antenna design for body-centric communications," International Journal of Antennas and Propagation, vol. 2021, Article ID 2360440, 14 pages, 2021.

[16] N. Chahat, M. Zhadobov, L. Le Coq, and R. Sauleau, "Wearable endfire textile antenna for on-body communications at $60 \mathrm{GHz}$," IEEE Antennas and Wireless Propagation Letters, vol. 11, pp. 799-802, 2012.

[17] M. Ur-Rehman, N. A. Malik, X. Yang, Q. H. Abbasi, Z. Zhang, and N. Zhao, "A low profile Antenna for millimeter-wave body-centric applications," IEEE Transactions on Antennas and Propagation, vol. 65, no. 12, pp. 6329-6337, 2017.

[18] Italian National Research Council, Dielectric Properties of Body Tissues in the Frequency Range $10 \mathrm{~Hz}$ to $100 \mathrm{GHz}$, Italian National Research Council, [Online]. Available: http://niremf. ifac.cnr.it/tissprop/, Italy.

[19] M. M. Khan, Q. H. Abbasi, A. Alomainy, C. Parini, and Y. Hao, "Dual band and dual mode antenna for power efficient body-centric wireless communications," in Proceedings of the IEEE International Symposium On Antennas and Propagation (APSURSI), pp. 396-399, Spokane, WA, USA, July 2011.

[20] S. H. Choi, J. Kim, J. K. Park, S. K. Kim, and J. Y. Park, "A new ultra-wideband antenna for UWB applications," Microwave and Optical Technology Letters, vol. 40, no. 5, pp. 399-401, 2004.

[21] B. Biscontini, S. Hamid, F. Demmel, and P. Russer, "A novel antenna for ultra wide band (UWB) intelligent antenna systems," in Proceedings of the IEEE MTT-S International Microwave Symposium Digestion, pp. 2023-2026, San Francisco, CA, USA, June 2006.

[22] A. Y. I. Ashyap, Z. Zainal Abidin, S. H. Dahlan et al., "Inverted E-shaped wearable textile antenna for medical applications," IEEE Access, vol. 6, pp. 35214-35222, 2018. 